\title{
Design and Manufacture of Solar-Powered Wheelchair
}

\author{
M. Pita ${ }^{1}$ \\ ${ }^{1}$ Department of Mechanical and Industrial Engineering, Faculty of Engineering and Technology, University of South Africa.
}

\begin{abstract}
This paper presents a study of a low-cost solar-powered wheelchair for disabled people of rural areas in South Africa. There are manual wheelchairs on the market which always require an able-bodied person to assist in steering the disabled person around. Other wheelchairs use a battery that is charged by electricity when it is flat. Electricity is expensive and scarce in rural areas. The main components of the solar-powered wheelchair are the wheelchair structure, solar panel, DC motor, charging controller, switch and wheels. The proposed design is very useful for physically disabled people of rural areas and affordable for the low-income earners of countries like South Africa. The wheelchair is cost effective, user friendly, selfdriven and independent. The solar-powered wheelchair will help physically disabled people with their daily movements and will be very effective in both rural and urban areas. The maximum speed and load that the wheelchair can handle are $11.25 \mathrm{~m} / \mathrm{min}$ and $155 \mathrm{~kg}$, respectively.
\end{abstract}

Keywords: Solar powered, wheelchair, motor, low cost and disability.

\section{INTRODUCTION}

Human-machine control interfaces have found many useful applications, some of which could be used to aid physically challenged people [1]. There is a growing and rich body of wheelchair research and development being generated around the world [2]. Wheelchairs are an important modality for mobility, activity and participation in life [2]. No one really knows when the first wheelchair was invented, although there are many who are willing to hazard a guess. What is interesting is that wheelchairs were not always invented for the right reason, especially where the Romans were concerned [3]. According to the latest global reports on disability, more than one billion individuals, constituting nearly $14 \%$ of the world population, live with a form of disability [4]. People with impaired mobility and balance, including lower limb amputees, those with spinal cord injuries, osteoarthritis, degenerative muscle and neurologic diseases are typical users of wheeled mobility devices [4]. The International Classification of Functioning, Disability and Health, which is the World Health Organization (WHO) framework for measuring health and disability at both individual and population levels, defines disability as "an umbrella term for impairments, activity limitations and participation restrictions" [5]. Manufacturers of wheelchairs have been rather conservative in introducing new ideas and have instead been content with minor product improvements, particularly with regard to powered wheelchairs
[6]. Haidar Taleb, a 47-year-old man from the UAE, displayed a rare combination of human spirit and willpower by building a wheelchair for himself which runs on solar power [3]. According to the UN Convention on the Rights of Persons with Disabilities, people with functional impairments should have the opportunity to experience personal autonomy, live independent lives and participate fully in all aspects of life on an equal basis with others [7]. Solar-powered wheelchair users may experience limitations in everyday life, leading to social exclusion and isolation, which has a negative effect on their health and psychosocial wellbeing [7]. Several studies have shown that both children and adults benefit substantially from access to a means of independent mobility, including power wheelchairs, manual wheelchairs, scooters, and walkers [8]. Independent mobility increases vocational and educational opportunities, reduces dependence on caregivers and family members and promotes feelings of self-reliance [8]. Every wheelchair consists of two engineering subsystems assembled into one structural and functional entity, such as the transport system which includes wheels, the drive, steering and braking mechanisms, and the orthotic system for body positioning which includes the body support system - back and side supports, seat, foot rest and other devices stabilising selected parts of the body [9]. There remains a vast need for quality wheelchairs around the world. The WHO estimates that $10 \%$ of people with disabilities (around 111 million) require a wheelchair and only about $5 \%-15 \%$ have access to an appropriate one, suggesting that the unmet need is approximately 95 million wheelchairs [10]. Nowadays electric wheelchairs extend the capabilities of traditional powered devices by introducing navigational intelligence and control [11]. Physically disabled people struggle to move themselves from one place to another on a daily basis. Manually operated wheelchairs do not fulfil their requirements. People who do not have hands require another person to move their wheelchair, which is a serious challenge to a physically disabled person who lives alone. The aim of this study was to design and manufacture an affordable solar-powered wheelchair, which is manually controlled, to overcome the above-mentioned challenge. The wheelchair uses the free energy from the sun. This design can be used in places where there is no electricity. Electricity is expensive and electric-powered wheelchairs require high maintenance compared to solar-powered wheelchairs.

\section{METHODOLOGY}

Preliminary ideas were gathered from different sources of literature and evaluated before the wheelchair was designed. 
Auto Desk Inventor 2019 was used to design the solar-powered wheelchair and is presented in Figure 1. The design was built at the workshop of the Mechanical and Industrial Engineering Department of the University of South Africa. The main components are a solar panel, battery charging controller, battery, DC motor, control switch and the frame. Radiation from the sun is converted into electrical energy by the solar panel. This energy from the sun is stored in the battery and it is regulated by a battery charging controller to prevent overcharging the battery. Stored energy is used to run the DC motor which is connected to the rear wheels. When the motor turns, the wheels also turn, and the wheelchair moves forward. Figure 2 shows a block diagram of the solar-powered wheelchair designed in this study.

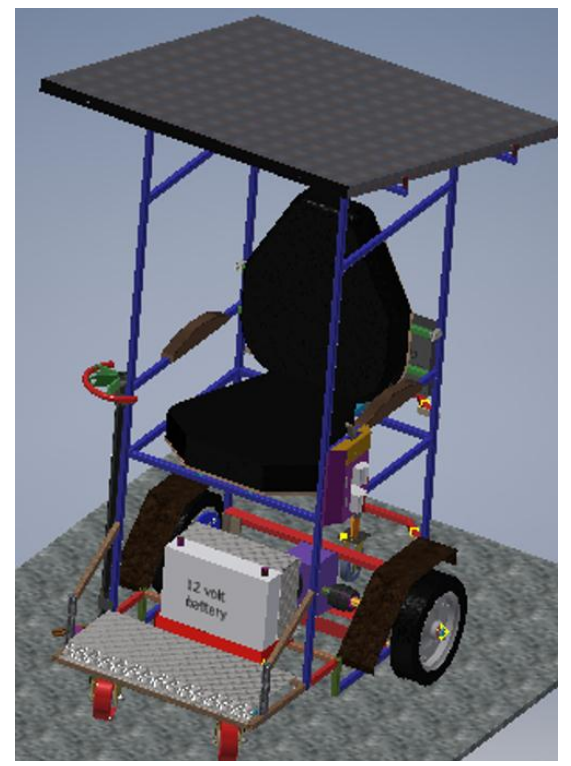

Figure 1: Design of solar-powered wheelchair

\subsection{Solar panel}

A solar cell, or photovoltaic cell, is an electrical device that converts the energy of light directly into electricity by the photovoltaic effect, which is a physical and chemical phenomenon [12]. Light shining on the solar cell produces both a current and a voltage to generate electric power [12]. The solar panel chosen was Solar Frontier KK with a peak power of $165 \mathrm{~W}$, peak voltage of $85.5 \mathrm{~V}$, peak current of $1.93 \mathrm{~A}$ and maximum system voltage of $1000 \mathrm{~V}$.

\subsection{Battery charging controller}

This is also known as a charging regulator. It regulates current from the solar panel into the battery to prevent overcharging. The battery charging controller found to be suitable for this design was the Firestar solar charge controller 20 A because of its price and user friendliness. This device also has a slot where a cell phone charger cable can be connected to charge a phone.

\subsection{Battery}

The power needed to run the DC motor comes from the rechargeable battery. There are different types and sizes of rechargeable batteries. The battery stores the energy from the sun, which is controlled by the charging controller. This energy is then converted into electric energy to run the motor. The battery used in this design was the Allgrand battery $12 \mathrm{~V} 100$ $\mathrm{AH}$ because of its availability and price.

\subsection{DC motor}

The motor converts electrical energy into mechanical energy. The conversion is done through the generation of a magnetic field by means of current flowing into one or more coils [12]. The DC motor is used to drive the wheelchair. It is connected to the rear wheels by couplings. The motor has a built-in gearbox which provides torque of $31.2 \mathrm{Nm}$.

\subsection{Frame}

The frame is the wheelchair skeleton. It holds the load of a person riding on it and of other components connected to it. It was made up of mild steel square tubes of $20 \times 20 \mathrm{~mm}$. The tubes were cut into different lengths according to the design dimensions and welded with $\mathrm{CO}_{2}$ welding so that it was strong enough to withstand the load and minimize vibration when moving. The maximum load the frame can carry is $155 \mathrm{~kg}$. The frame is $1300 \mathrm{~mm}$ high, $620 \mathrm{~mm}$ wide and $620 \mathrm{~mm}$ long.

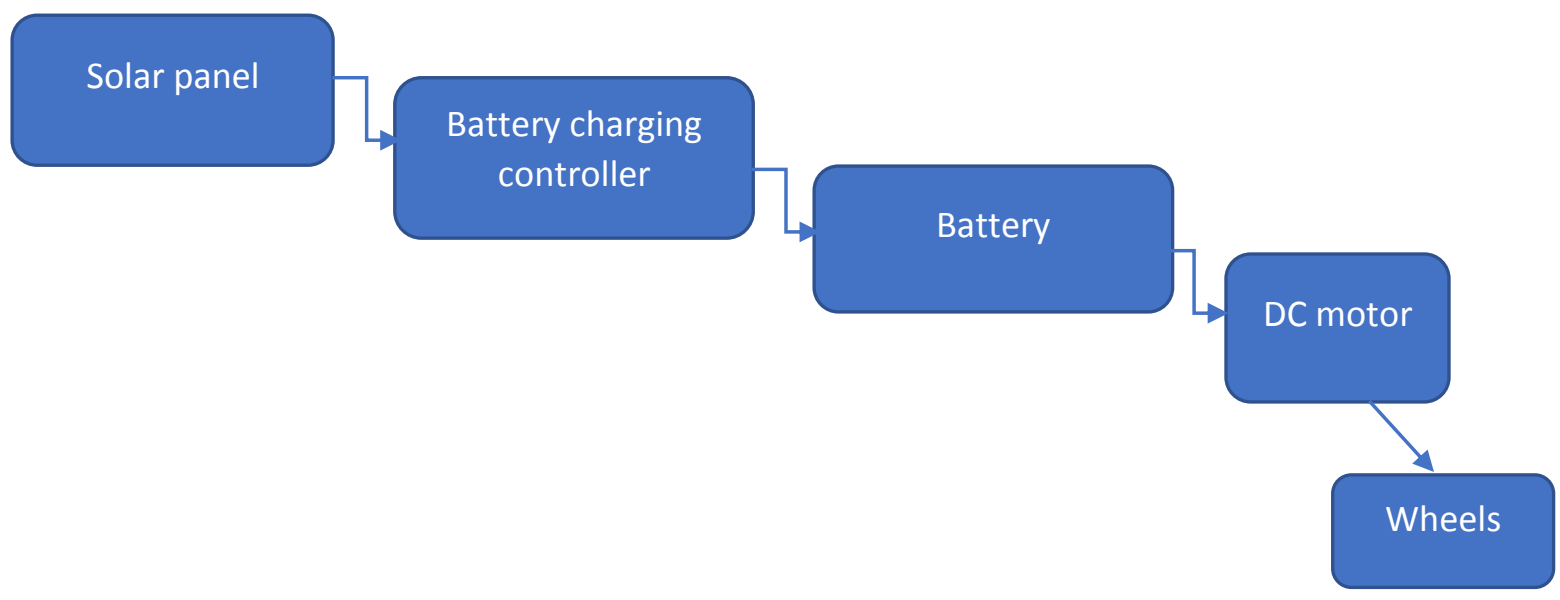

Figure 2: Block diagram of solar-powered wheelchair connection 


\section{RESULTS AND DISCUSSION}

The cost-effective and user-friendly solar-powered wheelchair was designed and manufactured as a mobility vehicle for disabled people to use on a daily basis. It was made with mild steel square tubes of $20 \times 20 \mathrm{~mm}$ with different lengths based on design diamensions. The wheelchair is powered by a single rechargeble Allgrand battery of $12 \mathrm{~V} 100 \mathrm{AH}$. A Frontier KK solar panel of peak power of $165 \mathrm{~W}$, peak voltage of $85.5 \mathrm{~V}$, peak current of $1.93 \mathrm{~A}$ and maximum system voltage of 1000 $\mathrm{V}$ was used to charge the battery. A Firestar solar charge controller of 20 A regulates the current going into the battery from the solar panel to protect the battery from overcharging. Two wires from the battery are connected to the DC motor to transmit the current from the battery to the motor. Two rear wheels are connected to the output shafts of the motor by two couplings. An on and off switch was connect to the motor to start and stop the wheelchair. Front wheels of $50 \mathrm{~mm}$ in diameter were made of cast steel and polymer tyres. The rear steel-plated wheels had a rubber polymer bearing with a diameter of $300 \mathrm{~mm}$. An aluminium plate $2 \mathrm{~mm}$ thick was used for the foot rest. Linkage type steering was used and the maximum speed of the wheelchair during testing was 11.25 $\mathrm{m} / \mathrm{min}$. The solar panel was also used to protect the driver from sunlight and rain. The maximum load the wheelchair can handle is $155 \mathrm{~kg}$. The driver can also charge a cellphone on this design. The complete solar-powered wheelchair is illustrated in Figure 3.

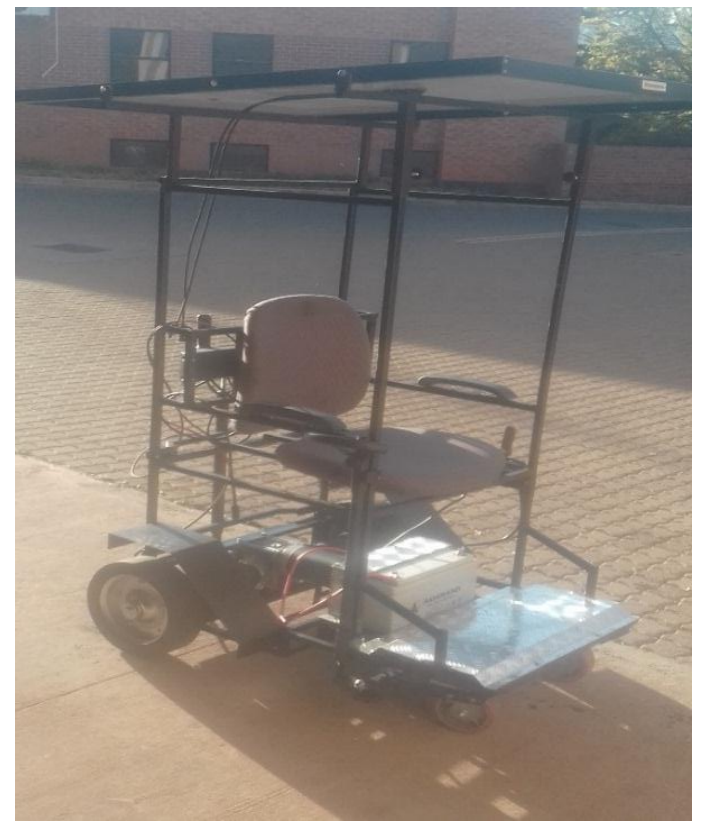

Figure 3: Solar-powered wheelchair

\section{CONCLUSION}

The design and manufacture of a mobility vehicle for disabled people which is powered by free sun radiation was successful. The wheelchair is user friendly, light, affordable and easy to operate and maintain. It can carry a maximum load of $155 \mathrm{~kg}$ and can travel at a maximum speed of $11.25 \mathrm{~m} / \mathrm{min}$. The recharging capacity of the panel is satisfactory. The wheelchair can travel for $6 \mathrm{~km}$ continuously. It runs more efficiently on flat surfaces than on an incline. The wheelchair is not foldable and can carry one person at a time. Apart from converting sun radiation to electric energy, the solar panel also protects the driver from sunlight and rain. The motor has a built-in reduction gearbox which produces torque of $31.2 \mathrm{Nm}$.

\section{FUTURE SCOPE}

A suitable variable speed drive needs to be installed to regulate the speed while driving.

\section{ACKNOWLEDGEMENT}

The author acknowledges the technical support of $\mathrm{Mr} \mathrm{O}$. Chego, a Mechanical Engineering student at the University of South Africa, Mr L.C. Lebea, a junior lecturer at the University of South Africa and financial support from the Mechanical Engineering Department at the University of South Africa.

\section{REFERENCES}

[1] M. S. Kaiser, Z. I. Chowdhury, S. Al Mamun, A. Hussain, and M. Mahmud, "Solar Powered Wheel Chair for Physically Challenged People Using Surface EMG Solar Powered Wheelchair for Physically Challenged People using Surface EMG Signal,” no. December 2015, 2016.

[2] R. A. Cooper, "Wheelchair research progress, perspectives, and transformation.," J. Rehabil. Res. Dev., vol. 49, no. 1, pp. 1-5, 2012.

[3] A. Manohar, P. S. V. R. Rao, and R. Dontikurti, "Solar Powered Wheel Chair : Mobility For Physically Challenged," vol. 2, no. 1, pp. 211-214, 2012.

[4] A. Ebrahimi, A. Kazemi, and A. Ebrahimi, "Wheelchair design and its influence on physical activity and quality of life among disabled individuals," Iran. Rehabil. J., vol. 14, no. 2, pp. 85-92, 2016.

[5] A. Davies and N. Christie, "An exploratory study of the experiences of wheelchair users as aircraft passengers implications for policy and practice," IATSS Res., vol. 41, no. 2, pp. 89-93, 2017.

[6] C. A. Mclaurin, "Current directions in wheelchair research," J. Rehabil. Res. Dev., vol. 27, no. SUPPL. 2, pp. 88-99, 1990.

[7] C. Blach Rossen, B. Sørensen, B. Würtz Jochumsen, and G. Wind, "Everyday life for users of electric wheelchairs - A qualitative interview study," Disabil. Rehabil. Assist. Technol., vol. 7, no. 5, pp. 399-407, 2012.

[8] R. C. Simpson, "Smart wheelchairs: A literature review," J. Rehabil. Res. Dev., vol. 42, no. 4, pp. 423-435, 2005.

[9] M. Sydor, A. Krauss, and H. Krauss, "Risk analysis for operating active wheelchairs in non-urban settings," Ann. Agric. Environ. Med., vol. 24, no. 3, pp. 532-536, 2017.

[10] A. Mhatre et al., "Developing product quality standards for wheelchairs used in less-resourced environments," 
International Journal of Engineering Research and Technology. ISSN 0974-3154, Volume 13, Number 9 (2020), pp. 2153-2156

(C) International Research Publication House. https://dx.doi.org/10.37624/IJERT/13.9.2020.2153-2156

African J. Disabil., vol. 6, pp. 1-15, 2017.

[11] P. S. S. Rashinkar, "SOLAR POWERED ELECTRIC WHEEL CHAIR,” no. March, pp. 35-38, 2017.

[12] M. Pita \& P.B. Sob, "DESIGN OF SOLAR -POWERED GRASS TRIMMER," in SAIIEneXXXt Proceedings, 30th September - 2nd October 2019, Port Elizabeth, South Africa (C) 2019 SAIIE, 2019, no. October, pp. 1-8. 